\title{
A EDUCAC̣ÃO CIENTÍFICA COMO ELEMENTO DE DESENVOLVIMENTO HUMANO: UMA PERSPECTIVA DE CONSTRUÇÃO DISCURSIVA
}

\author{
Carmen Irene Correia de Oliveira*
}

RESUMO: O artigo discute a produção discursiva sobre educação científica, considerando a rede de sentidos formada pelas noções de cultura científica, divulgação, popularização e alfabetização científica. Foi realizada uma análise do documento Cultura Científica: um direito de todos. Adotou-se o referencial teórico-metodológico da análise de discurso francesa e foi efetuada uma revisão de literatura sobre tais noções. A partir do levantamento dos termos-chave cultura científica, alfabetização científica, educação científica e divulgaşão científica, em todo documento, focalizou-se a apresentação da obra e os artigos nos quais esses termos estão presentes. Uma leitura dos artigos vai indicar que a questão da cultura científica está fortemente atrelada à educação, fazendo com que os argumentos se construam no contexto de formações discursivas engendradas na articulação ensino-tecnologia-ciência.

Palavras-chave: Cultura científica. Educação Científica. Análise do discurso.

\section{SCIENCE EDUCATION AS AN ELEMENT OF HUMAN DEVELOPMENT: A DISCURSIVE PERSPECTIVE}

ABSTRACT: The article discusses the discursive production of science education considering the network of meanings formed by notions of scientific culture, dissemination, popularization and scientific literacy. An analysis was carried out on the document Cultura Cientifica: um direito de todos (Scientific Culture: a right of all). We adopt the French theoretical and methodological framework of discourse analysis, and a literature review of such notions was conducted. In the survey of the keywords scientific culture, scientific literacy, science education and popularization of science, we focused on the Presentation of the document and on the articles in which these terms are present. A reading of the articles will indicate that the issue of scientific culture is strongly linked to education, causing the arguments to be constructed in the context of discursive formations engendered in the teaching-science-technology.

Keywords: Scientific culture. Science Education. Discourse analysis. 


\section{INTRODUC̣̃̃o}

O desenvolvimento científico transformou mentalidades, visões de mundo, práticas educacionais e passou a funcionar como sistema explicativo dos fenômenos naturais.

Essa trajetória envolveu um alto grau de especialização que trouxe consequências para as sociedades científicas, que se transformaram em grupos de eruditos; para as revistas, que começaram, também, a se especializar; e para a linguagem que os cientistas utilizavam para comunicar suas descobertas. Em pouco tempo, a divulgação da ciência tinha dois objetivos: adaptação para os leigos e informação para os cientistas de outras áreas que tivessem interesse (SANCHEZ MORA, 2003, p. 23).

Atualmente, observa-se que aquilo que é produzido pela ciência não é de interesse somente dos cientistas. A questão que se coloca é como as descobertas científicas podem chegar ao conhecimento não somente daqueles que estão envolvidos com a ciência, como também do cidadão, aquele que, em virtude das grandes mudanças que o binômio ciência-tecnologia introduz na sociedade, deve ser esclarecido sobre os rumos que a civilização pode estar tomando. Sendo assim, tendo em vista a condição que a ciência ocupa nos espaços da cultura humana ocidental e as discussões em torno da educação científica, problematizar as condições de circulação dos construtos discursivos que trazem à luz as descobertas e avanços científicos realizados pode ser considerada uma tarefa de relevância. Isso porque o processo decisório, em diferentes níveis, deve ser guiado por um nível adequado de informação.

No entanto, considerando o macrocontexto, pressupomos uma etapa anterior, e necessária, que consiste na problematização dos discursos sobre a cultura científica e seus correlatos, tendo em vista os sentidos que são gerados nas estratégias da educação científica e da ciência para todos.

O presente artigo apresenta uma discussão dos sentidos produzidos em torno da educação científica no documento Cultura Científica: um direito de todos. Tomamos essa ideia como central e a abordamos, também, em sua relação de significado com outros termos, como alfabetização cientifica, divulgação científica, popularização da ciência e cultura cientifica. Essa relação é delineada a partir da leitura e da discussão de artigos e livros que tratam do tema educação científica atrelada à cultura cientifica. $\mathrm{O}$ estatuto atribuído ao documento Cultura Científica vem da própria apresentação, que indica o livro como "uma contribuição da UNESCO para um momento estratégico da educação brasileira" (WERTHEIN, 2003, p.7). Trata-se de um texto elaborado a partir de perspectivas acerca de uma determinada situação mundial referente ao ensino de ciências e que conta com diferentes contribuições. Essa discussão está inserida no contexto de uma pesquisa institucional que articula a educação a questões relativas aos processos informacionais envolvidos em produtos culturais.

A proposta deste trabalho consiste em apresentar uma análise discursiva do documento Cultura Científica: um direito de todos, tendo em vista os modos como as noções já citadas são entendidas e rearticuladas na argumentação a favor de uma cultura 
científica apresentada como direito de cidadania. Esse caminho leva, necessariamente, à discussão do próprio estatuto da ciência e da tecnologia na nossa sociedade.

Este artigo apresenta, inicialmente, um panorama sobre cultura científica, alfabetização e divulgação cientifica; em seguida, apresenta uma análise e faz considerações sobre o modo como se articulam os sentidos em torno da cultura científica. Fundamentalmente, é possível perceber, pela análise, que o sentido é construído, nos discursos focalizados, fortemente relacionado ao de alfabetização científica ou educação científica, tomando tópicos como tecnologias de comunicação e informação, instituição escolar e formação de professores como fios condutores de propostas reformadoras. Cabe ressaltar que um dos nossos pressupostos é o de que documentos internacionais sobre essa questão pautam as orientações e discursos em âmbito nacional. Sendo assim, falamos sobre e adotamos práticas que se baseiam em protocolos internacionais e que situam o desenvolvimento econômico e social no quadro maior do desenvolvimento tecnológico e científico.

Outra questão a ser assinalada é que verificamos, indo ao encontro do que a leitura de diferentes autores nos mostra, que nesse documento não é possível discutir ou abordar cultura científica sem, o que passamos a denominar, seus correlatos: alfabetização e divulgação científica.

\section{UM PANORAMA SOBRE AS NOCְÕES DE ALFABETIZAC̣ÃO, CULTURA E DIVULGAÇÃO CIENTÍFICA}

De acordo com a literatura, abordar a cultura científica é considerar, também, os processos denominados como educação cientifica e alfabetização científica. Em alguns casos, nas discussões feitas por alguns autores, são arrolados os conceitos de divulgação científica e popularização da ciência, como nos indicam Auler e Delizoicov (2001) ao abordarem a questão da alfabetização científico-tecnológica. Muitos artigos estão impregnados da urgência de uma reformulação no ensino de ciências que tenha como base uma perspectiva de construção de cidadania. Assim, nesse contexto, a alfabetização científica acaba sendo considerada uma das potencialidades em processos de democratização.

Durant (2005) afirma que scientific literacy (traduzido no texto por alfabetização científica) é um termo da moda no campo da educação tanto nos EUA quanto na Inglaterra. E esse termo designa "o que o público em geral deveria saber a respeito de ciência" (p. 13). O autor apresenta três abordagens para o termo. Na primeira, alfabetização científica diz respeito ao conhecimento do conteúdo da ciência; na segunda, o termo se refere à importância de dominar os procedimentos mentais e manuais de produzir conhecimento científico (método científico); a terceira relaciona-se à ideia de cultura científica, pois enfatiza as estruturas sociais ou as instituições da ciência.

Araújo, Caluzi e Caldeira (2006) mostram que a alfabetização científica tem, de acordo com alguns pesquisadores, um foco no indivíduo, como afirmam Polino e Vogt em Percepşão pública da ciência. Nesse trabalho, os dois autores consideram 
que alfabetiz̧ação cientifica e cultura científica não são equivalentes, pois a primeira se centra no indivíduo, ao passo que a segunda demanda um olhar que dê conta das instituições, dos grupos de interesse e da difusão da ciência na sociedade. Assim, a primeira seria mais "individual" e a segunda, "social".

Outra definição apresentada por Araújo, Caluzi e Caldeira (2006) é a de Bybee, segundo a qual a alfabetização científica está relacionada a "[...] um continuum de conhecimentos e práticas sobre o mundo natural e artificial, com diferentes graus e níveis em função da idade, da cultura e do meio social"' (p. 16). Nesse sentido, a alfabetização é entendida como um processo.

Partindo de tais considerações, os autores discutem uma concordância entre as definições em entender a alfabetização científica com base no acúmulo de conhecimento científico. Além disso, eles mostram como o termo teve uma mudança em função do contexto histórico. Nas décadas posteriores à Segunda Guerra Mundial (1950 a 1960) a concepção de alfabetização científica estava atrelada à compreensão (ensino) de conceitos e métodos científicos, justificada pela preocupação norte-americana em formar cientistas no contexto da guerra fria, principalmente após os russos terem lançado o primeiro satélite, o Sputnik, antes dos americanos: "Naquele contexto, os americanos subsidiaram projetos que incentivavam os jovens a seguir a carreira científica" (ARAÚJO; CALUZI; CALDEIRA, 2006, p. 17). No final dos anos de 1960, o movimento de Educação em Ciência, Tecnologia e Sociedade surge na Grã-Bretanha em decorrência dos questionamentos oriundos das expectativas, não totalmente contempladas, sobre desenvolvimento científico. Tal movimento consolida-se nos anos de 1990, e a alfabetização científica, nesse contexto, passa a ser percebida como uma "[...] preocupação em formar cidadãos aptos a tomarem decisões com responsabilidades sobre assuntos referentes à Ciência e à Tecnologia e os seus determinantes políticos, sociais e econômicos" (ARAÚJO; CALUZI; CALDEIRA, 2006, p. 14).

Segundo os autores,

"Para que uma sociedade seja considerada alfabetizada cientificamente é imprescindível que o cidadão esteja imerso no segundo estágio da cultura científica. Faz-se necessário que a cultura científica esteja inserida à cultura geral. Isso somente ocorre quando há acesso a informações e conhecimentos suficientes para possibilitar que os cidadãos os incorporem ao seu cotidiano" (ARAÚJO; CALUZI; CALDEIRA, 2006 p. 19)

A alfabetização científica, para Bauer (apud EPSTEIN, 2002, p. 11), abrange três componentes culturais: 1 - uma noção geral sobre determinados conceitos e temas da ciência; 2 - uma noção sobre a natureza da atividade científica; 3 - uma consciência do papel da ciência na sociedade e na cultura.

Em tal perspectiva, é possível reconhecer uma ligação entre o que o cidadão comum deve conhecer sobre ciência, o que se c onsidera um nível ideal para esse conhecimento e o esclarecimento público sobre os rumos das políticas de pesquisa científica.

A alfabetização científica tem foco no cidadão. No entanto, sua perspectiva é social. Tendo em vista as condições contemporâneas dos debates sobre o 
desenvolvimento tecnológico, o desenvolvimento industrial e o desenvolvimento econômico que estão atrelados ao fomento científico, há de se considerar a importância de alfabetizar o cidadão no conhecimento que se tornou determinante para responder às várias problemáticas da sociedade. Como afirma Epstein (2002, p.12), o que se deseja é que o cidadão tenha noções suficientes de como funciona o mundo e os paradigmas científicos, de modo a se situar de forma consciente nos debates polêmicos em torno, por exemplo, do aproveitamento da energia nuclear e do destino dos resíduos nucleares, do cultivo de vegetais transgênicos e das questões que envolvem as terapias genéticas, não sendo apenas "caudatário de correntes de opinião, muitas vezes alimentadas menos pelo interesse público do que por lobbies e interesses de grupos e facções interessadas".

Chassot (2003) considera que a alfabetização científica pode potencializar projetos de uma educação mais comprometida, ou seja, ela representa uma possibilidade de corrigir as práticas conteudistas no ensino de ciências. $\mathrm{Na}$ sua perspectiva, a ciência é uma linguagem construída para a compreensão do mundo natural. Logo, compreender ciência é saber ler a linguagem na qual está escrita a natureza. "É um analfabeto científico aquele que é incapaz de uma leitura do universo" (CHASSOT, 2003, p.91). Compreender a ciência habilita o sujeito a tomar decisões e a compreender fatores relativos às consequências do avanço científico. Assim, a alfabetização científica pode ser considerada como um processo de levar o sujeito a compreender essa linguagem, a ler nessa linguagem que é utilizada para explicação do mundo natural.

Assim, poderíamos pensar que alfabetização científica signifique possibilidades de que a grande maioria da população disponha de conhecimentos científicos e tecnológicos necessários para se desenvolver na vida diária, ajudar a resolver os problemas e as necessidades de saúde e sobrevivência básica, tomar consciência das complexas relações entre ciência e sociedade (FURIÓ et al., 2001).

Alfabetização cientifica seria, enfim, um processo pelo qual os estudantes, futuros cidadãos, compreendem os conhecimentos, procedimentos e valores relativos à ciência de modo a tomar decisões e a perceber tanto as utilidades da ciência quanto suas limitações e consequências negativas.

Utilizando, alternadamente, os termos alfabetização cientifica e educação científica, Santos (2007) afirma que a primeira passou a ser mais discutida no início do século XX, destacando o papel de John Dewey nesse sentido, nos Estados Unidos.

A cultura científica, por seu turno, parece ter uma ligação estreita com a alfabetização científica, mas não se confunde com ela. Só é possível haver cultura científica se houver alfabetização científica. Denominada scientific literacy por alguns grupos de pesquisadores norte-americanos; public understanding of sciense na Inglaterra; e culture scientifique na França, a cultura científica é um conceito elaborado por E.D. Hirsch em 1987 e designa tudo que o público deveria saber sobre ciência. A proposta de Hirsch era de que a cultura científica incluiria cerca de 5.000 conceitos considerados essenciais, dando conta da maior parte da instrução escolar. "A ideia é 
que o público que vive no seio de uma civilização científica e tecnológica complexa deveria possuir certos conhecimentos científicos" (EPSTEIN, 1992, p. 111).

Os benefícios gerados por uma cultura científica foram elencados por Fourez (apud EPSTEIN, 2002): 1 - Ela possui objetivos humanísticos, pois permite ao sujeito usufruir suas potencialidades sobre essa cultura; 2 - Ela abriga objetivos econômicos, pois está relacionada, à adaptação do indivíduo à pressão social e econômica, o que aumenta a empregabilidade, e ao crescimento da produtividade e da economia do país; 3 - Ela promove a democracia ao possibilitar que os sujeitos participem dos debates públicos.

Alfabetização científica e cultura científica, desse modo, encontram-se no centro de debates que investem nas questões educacionais e informacionais, tendo em vista não somente o esclarecimento, mas, sobretudo, a construção de um conhecimento sobre a ciência em diferentes esferas da sociedade.

Parece restar pouca dúvida sobre a relação entre os processos de popularização ou vulgarização da ciência e a construção de uma cultura científica que promova, nas mais diferentes esferas das atividades humanas, o contato mais direto, e por que não dizer, mais crítico, com a ciência e seus efeitos. Se por um lado muitos consideram perigoso expor o público comum a uma "meia-ciência", por outro o contexto contemporâneo coloca esse processo como urgente, tendo em vista as demandas crescentes de áreas profissionais direta ou indiretamente ligadas ao campo científico, como o que acontece na indústria, por exemplo.

[...] A técnica moderna evolui para um estado racional, muito mais preciso e de rendimento muito maior. A difusão científica traria como resultado a familiaridade de todos com as coisas da ciência e, sobretudo, uma confiança proveitosa nos métodos científicos, uma consciência esclarecida dos serviços que estes podem prestar (ALMEIDA, 2002, p. 68-69).

No conjunto de trabalhos e pesquisas sobre o tema, o papel da educação nos espaços não formais de aprendizagem é o mais enfocado. Silva; Arouca; Guimarães (2002), por exemplo, destacam três objetivos básicos das ações de popularização da ciência: 1 - afirmar o direito de cidadania com relação ao conjunto das questões científicas e tecnológicas; 2 - despertar vocações científicas nos jovens; 3 - gerar parâmetros para a própria comunidade científica.

Nesse ponto, faz-se necessário discorrer sobre divulgação científica, processo estreitamente ligado às questões anteriores, e que apesar de não estar contemplado nos discursos analisados, merece destaque.

Comumente, a divulgação científica é entendida como o modo de difundir o conhecimento produzido no campo científico para fora do seu contexto originário. É nesse sentido que termos como difusão científica e popularização da ciência também convivem na mesma esfera de discussão. De acordo com Bueno (1984), difusão científica consiste em um gênero que abarca a disseminação científica e a divulgação científica. A primeira, para ele, consiste na difusão da informação para especialistas, a segunda, na difusão para o público em geral Por outro lado, Perez e Caluzi (2006) concordam com a tese de que a divulgação científica consiste na 
reformulação de um discurso científico em um discurso adaptado para o público em geral, mas ressaltam que tal processo não é simples e direto. Nesse sentido, segundo eles, "Para que o grande público reconheça a amplitude do termo Ciência, uma boa matéria de divulgação científica é imprescindível” (p. 57). Strack; Loguércio e Del Pino (2009) pensam no discurso da divulgação científica como um "espaço discursivo intervalar" (cf. Grigoletto, 2005) e apontam para a relação entre os conceitos alfabetização discursiva, divulgação científica e cultura científica que ocorre nesse espaço. Tal ligação pode ser de complementação ou de confronto, mas sempre lança significações sobre a relação comunicativa entre ciência e sociedade. O que podemos observar é que uma das questões centrais da divulgação é o discurso; uma outra é o contexto. Assim, discurso e ideologia encontram-se na encruzilhada dessa discussão que envolve aqueles que fazem ciência, um espaço de mediação ocupado por aqueles que trabalham nas atividades comunicativas e, por fim, aqueles que consomem a informação divulgada. Aliada a tais questões há, ainda, os meios de circulação dessa informação. Desse modo, Perez e Caluzi (2006) afirmam que a divulgação científica estrutura-se em níveis que têm como função a transmissão da informação científica que, por sua vez, deverá ser trabalhada conforme o grau de compreensão do público-alvo, "seguindo não a lógica do discurso científico, e sim a racionalização do discurso de comunicação a partir da Ciência” (PEREZ; CALUZI, 2006, p. 59). Podemos perceber, nesse caso, que há um campo no qual os processos discursivos devem ser focalizados não somente a partir dos referenciais da ciência que é alvo da divulgação.

\section{AS ANÁLISES}

A investigação foi feita com base nos estudos realizados pela análise do discurso de vertente francesa, que contempla a perspectiva de discursos atrelados ao contexto sócio-histórico e ideológico de produção e mantém uma relação entre o dizer e as condições de produção desse dizer, percebendo a linguagem como uma prática social e histórica.

A nossa opção se pauta em uma perspectiva que toma "[...] o discurso como possibilidade de abordagem dos estudos do homem com o ideológico e, conseqüentemente, com suas representações e com o mundo que constrói e reconstrói para si e para os outros [...] (OLIVEIRA; ORRICO, 2005, p. 78). Em um contexto no qual a ciência tornou-se o pano de fundo para as questões que o homem coloca e, também, para as respostas que ele procura, consideramos importante abordar os discursos que tomam esse saber em um jogo de legitimação, compreendendo que tais discursos sobre a cultura científica constituem um conjunto no universo de formação discursiva sobre a ciência.

A orientação mais comum que a literatura da área (teorias do discurso e análise do discurso) tem nos mostrado é a de considerar, inicialmente, os objetivos do estudo e adotar alguns princípios já consagrados no meio (RICOUER, 1999): 
a) o discurso é um evento, um acontecimento que se realiza em um contexto determinado, envolvendo sujeitos que ocupam lugares específicos nesse processo. Esses lugares correspondem a funções dentro de uma estrutura social;

b) o discurso é o locus de cristalização das significações ideológicas que controlam sua produção;

c) o discurso associa-se a condições de produção determinadas, ou seja, envolve um gênero discursivo determinado (artigo de jornal, romance, etc.). Essas considerações nos impedem de definir o discurso como uma simples sucessão de frases, para demarcá-lo em função de fins específicos do estudo a ser compreendido. Por isso, Osakabe (1999, p.8), em seu trabalho, propõe abordar o discurso como realidade empírica sobre a qual incidirá a análise. “[...] Entende-se como realidade empírica um objeto delimitável no tempo e no espaço, perceptivelmente observável e compreensível, e analisável em seus elementos recorrentes." Assim, podemos perceber que a análise do discurso de origem francesa (AD) estabelece uma relação entre o dizer e as condições de produção desse dizer, percebendo a linguagem como uma prática social e histórica, tornando-se a opção mais viável ao projeto que empreedemos.

Em termos analíticos, como afirma Orlandi (1999), o texto é o objeto material que o analista tem diante de si e, nesse sentido, deve ele perceber que esse texto remete a um discurso que, por sua vez, forma-se nas estratégias de uma determinada formação ideológica. O discurso não está dado; chega-se a ele por meio da análise de sua materialidade. Nesse momento, "estamos em condição de desenvolver a análise, a partir dos vestígios que aí vamos encontrando [...]”.

Um dos problemas que se coloca no trabalho com AD é o da delimitação do enunciado, conceito central dos processos de identificação dos "vestígios". A partir de Ducrot e Foucault, entendemos o enunciado para além da fronteira da frase, e considerando a natureza dos nossos documentos, a delimitação do enunciado em torno dos termos-pivôs foi facilitada. Mainguenau apresenta dois exemplos de trabalho de análise com termos-pivôs que se desenvolveram de forma diferente. No primeiro, o estudo dos manuais escolares da III República Francesa, focalizando os deslizes metafóricos de "mãe" para "Pátria"; o termo não é escolhido "em função de um saber histórico anterior, mas definido durante a análise." No segundo, um trabalho sobre discursos xenófobos suíços, "inscreve-se em um procedimento diferente, [pois] parte do princípio que duas palavras, Überfremdung (“dominação e superpopulação estrangeiras") e xenofobia, representam, desde o início dos anos 60, na Suíça, fórmulas dominantes. O método dos termos-pivôs dominou os trabalhos da AD logo no seu início, consistindo em "selecionar a priori algumas palavras-chave (os termos-pivôs), consideradas representativas de uma formação discursiva, depois em construir um corpus com todas as frase onde figuravam essas palavras (MAINGUENEAU, 1997). A partir dessas concepções, e considerando as discussões em torno de cultura científica, divulgação e alfabetização científica, delimitamos nosso corpus". 
Os seguintes procedimentos foram efetuados: a) levantamento inicial de termos-chave (cultura científica; alfabetização científica; educação científica; divulgação científica), selecionados a partir do campo teórico que sustenta as discussões; b) seleção dos artigos do livro Cultura Científica com base no quantitativo dos termos-chave; c) análise da materialidade discursiva com seleção dos enunciados nos quais os termos-chave apresentam centralidade, de modo a perceber como são produzidos os sentidos em torno de tais expressões.

Antes de apresentarmos a análise do documento em pauta, cabe uma breve contextualização, a fim de verificar a emergência das redes de sentidos que se constroem em diferentes espaços discursivos e que agenciam outros elementos para tornar concreta uma ideia de desenvolvimento global necessário no âmbito do organismo internacional que, de certo modo, assina o documento que vamos analisar.

No site da Unesco, ao seguirmos pelos itens Natural Sciences, Priority Areas, Science Education, chegaremos à apresentação do Science Education Programme, que consolida uma ideia que tem lastreado a educação científica desde meados do século XX: a de que o desenvolvimento em ciência e tecnologia é um índice para determinar o quanto um país é desenvolvido.

Capacidade em ciência e tecnologia é um elemento chave no desenvolvimento econômico e social. Promover a educação científica a todos os níveis de escolaridade e alfabetização científica na sociedade em geral é um alicerce fundamental para a construção de capacidade de um país em ciência e tecnologia. A educação científica tem sido uma prioridade para a UNESCO desde sua criação.

Ciência, tecnologia, engenharia e educação matemática (STEM) são importantes para o desenvolvimento, assim como para os países desenvolvidos, para aumentar a consciência pública, compreensão e respeito para com a alfabetização em engenharia, ciência e tecnologia, e também para permitir aos países em desenvolvimento a criar uma massa crítica de cientistas, pesquisadores e engenheiros que lhes permitam participar plenamente na economia global. Particular ênfase é dada para encorajar os jovens, especialmente jovens, para prosseguir uma carreira científica. [...] (UNESCO, acessado em 11/2010).

Essa Apresentação funciona como um dos elementos da contextualização do processo de fortalecimento da educação científica, tendo em vista um panorama maior de crescimento econômico e superação da pobreza e de desigualdades entre os países e neles mesmos. Acreditamos que os documentos internacionais pautam as ações nacionais, como podemos observar no site da Unesco no Brasil. No item Ciências Naturais, encontramos a apresentação da Educação Científica no Brasil:

O grande desafio do país é fazer com que os investimentos realizados no ensino de ciências cheguem cada vez mais de forma homogênea à população e possam efetivamente melhorar a sua qualidade de vida. [...]

A UNESCO tem importante papel a desempenhar no avanço da educação científica, e também na política de Ciência e Tecnologia. Particularmente, iniciativas devem ser implementadas com vistas a fortalecer o ensino científico nas escolas do ensino fundamental e médio. 
De conformidade com a Conferência Mundial sobre Ciência de Budapeste, a UNESCO deverá apoiar os esforços nacionais que visem promover a inclusão social por meio de estratégias para o uso da informação em Ciência e Tecnologia. (REPRESENTAÇÃO DA UNESCO NO BRASIL, acessado em 11/2010).

É possível perceber a rede de referências que funciona para contextualizar o debate em dois níveis que poderíamos identificar como global e local, por meio de apoio de um órgão como a Unesco às políticas nacionais de desenvolvimento em ciência e tecnologia. A referência a outros documentos traz uma relação forte de intertextualidade marcada pela necessidade de construção de políticas desenvolvimentistas, para as quais as metas são a educação científica e o ensino de ciências.

O documento Cultura Cientifica traz autores de diferentes nacionalidades: francesa, brasileira, argentina e espanhola. Ele é composto de uma apresentação, um abstract e cinco artigos. A partir de um levantamento quantitativo inicial, é possível verificar que:

- A expressão cultura científica é usada cinco vezes no artigo "A renovação do ensino das ciências no contexto da reforma da educação secundária" e três vezes em "Educação científica: sim, mas qual e como?”.

- A expressão alfabetização científica é usada duas vezes no artigo "Educação científica: sim, mas qual e como?" e uma vez no artigo "A contribuição da educação secundária à formação de cidadãs e cidadãos para uma sociedade sustentável".

- A expressão educação científica, por sua vez, é usada dezesseis vezes (sem contar sua presença em títulos de capítulos e subitens), sendo que aparece uma vez no artigo "A renovação dos ensino das ciências no contexto da reforma secundária"; oito vezes no artigo "Educação científica: sim, mas qual e como?" e sete vezes no artigo "A contribuição da educação secundária à formação de cidadãs e cidadãos para uma sociedade sustentável”.

- A expressão divulgação científica não aparece no documento, apesar de ser um dos descritores da ficha técnica do livro.

Uma leitura dos artigos indica que a questão da cultura científica está fortemente atrelada à educação, fazendo com que os argumentos se construam no contexto de formações discursivas engendradas na articulação ensino-tecnologia-ciência.

Tendo em vista o levantamento inicial, três artigos foram selecionados para análise: "A renovação do ensino das ciências no contexto da reforma da educação secundária", "Educação científica: sim, mas qual e como?" e "A contribuição da educação secundária à formação de cidadãs e cidadãos para uma sociedade sustentável".

\section{“A renovação do ensino das ciências no contexto da reforma da educação secundária”} por Albert Sasson 
A discussão desse tema está explícita no título, que menciona a renovação do ensino de ciências e atrela tal processo à questão da cultura científica. Vejamos dois enunciados do artigo:

Enunciado 01 - Assim, como enfrentar esta acumulação de conhecimentos científicos no ensino das ciências no nível da escola e da educação secundárias? Como fazer isso para todos, ou seja, combinando a ciência com a equidade? Como elevar o nível médio de cultura científica e tecnológica dos cidadãos, que não está à altura das expectativas de uma sociedade modelada fortemente pela ciência e tecnologia, e que precisa, também, avaliar os benefícios e as desvantagens da ciência e da tecnologia?" (p. 14).

Enunciado 02 - "Em outras palavras, o desenvolvimento da cultura científica, para a qual contribui o ensino das ciências e da tecnologia na escola e no colégio, é uma prioridade para as sociedades contemporâneas e para cada um dos seus cidadãos" (p. 14).

O enunciado 01 é formado por uma série de questões que funcionam como desencadeadores da argumentação que o autor se propõe a apresentar. Tais questões são construídas em escala crescente de relação, que coloca, ao final, a importância de "conhecer mais sobre ciência" para a sociedade. Na primeira questão temos o verbo "enfrentar" indicando o problema a ser encarado e vencido: o acúmulo de conhecimentos científicos no nível da escola. Na segunda, temos o "fazer com equidade", ou seja, igualitariamente, em todos os níveis escolares e socioeconômicos. Na terceira, o verbo "elevar" aparece relacionado ao nível de cultura científica do cidadão de modo que ele possa avaliar as consequências da ciência e da tecnologia. Podemos entender que as três questões vão do campo da educação formal (nível da escola e da educação secundária) à cultura científica (nível mais abrangente da formação, considerando espaços formais e não formais). Em seguida, o enunciado 02 surge como uma síntese das inquietações presentes nas perguntas, mas também como uma apresentação/preparação para a resposta/ projeto. Nele, temos a relação simétrica de causalidade: o ensino de ciências (nos níveis fundamental, básico e médio) contribui para o desenvolvimento da cultura científica e esta é uma prioridade para a sociedade.

A afirmativa indica a prioridade dessa cultura científica. Há uma explicitação do valor e do peso da ciência e da tecnologia na sociedade que são enfatizados pelo uso do adjetivo modelada reforçada pelo advérbio fortemente. Tendo estabelecido que a sociedade contemporânea é marcada pela C\&T, cabe ao ensino um papel fundamental no incremento da cultura científica. O contexto, então, é marcado pela circularidade: 


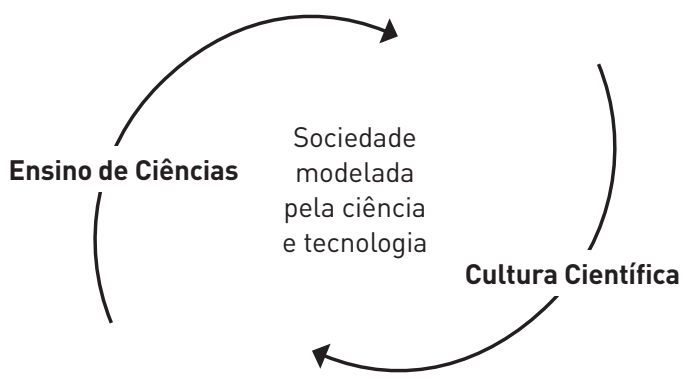

Seguindo sua argumentação, o autor destaca a centralidade do impacto das novas tecnologias de comunicação e informação em diferentes aspectos da vida humana e afirma: "é lógico supor que as instituições educativas, como instituições sociais, se vejam marcadas fortemente influídas por essas novas tecnologias" (p. 16). Tal influência será determinante para se pensar novas formas de ensino-aprendizagem. Também atrelada a essa perspectiva, destaca-se uma outra relação: o aumento do volume informacional e o desenvolvimento de uma cultura de constante formação fez com que "a instituição escolar tenha deixado de ser o centro de explosão e geração de informação" (p. 17). Desse modo, temos um caminho que nos leva até a introdução dos novos espaços de aprendizagem. No contexto de desenvolvimento de novas tecnologias de comunicação e informação e aumento exponencial de produção de informação, observa-se um impacto nas instituições educativas e a consequente transformação da instituição escolar tradicional, não sendo ela mais o centro de produção (e consumo) de informação.

Com essa transformação, retorna-se às TICs que passam a ter um papel central na circulação de informação. Destacando algumas críticas com relação à "utopia educativa" que preconiza estar "o conhecimento situado em qualquer parte do ciberespaço à disposição de qualquer pessoa" (p. 18), o autor mostra que informação e conhecimento não são sinônimos e que o fator humano (o professor) ainda tem papel fundamental no processo, sendo necessário que "a instituição escolar e os que dela participam" se adaptem às novas circunstâncias. Nessa rede de significados, as TICs e o novo contexto cultural "que modela nossa sociedade com base na C\&T" estão entrelaçadas às mudanças necessárias à instituição escolar e seus atores, levando-nos a entender que os sentidos que são construídos em relação à cultura científica estão sedimentados no espaço da ciência como campo hegemônico, e na educação como elemento de transformação.

\section{"Educação científica: sim, mas qual e como?" por Beatriz Macedo e Raquel Katzleowicz.}

O argumento inicial das autoras está pautado no combate à exclusão social, tomando educação científica com uma estratégia de neutralização desse problema. Vejamos um dos enunciados: 
Enunciado 03 - [...] o acesso aos conhecimentos científicos pode ser mais um instrumento de exclusão de mulheres e homens que vivem e atuam em sociedades modeladas pela ciência e tecnologia. Esta exclusão tem resultado na criação de uma elite à qual se reserva a ciência e a tecnologia, enquanto a maioria da população não tem a formação científica adequada (p. 62).

O primeiro destaque é o verbo "modelar" novamente presente com relação ao modo como a ciência e a tecnologia se relacionam com a sociedade - modelando-a.

O segundo destaque é obtido por meio de uma estratégia de substituição para ressaltar a associação entre conhecimento científico e capital. Tomando o segmento "criação de uma elite que tem acesso à ciência e à tecnologia", podemos fazer uma troca com uma expressão cuja ideia central é a distribuição de riqueza e teremos "criação de uma elite que tem acesso à maior parte da riqueza", ao passo que os excluídos, "a maioria da população não tem a formação científica adequada", são aqueles que "não têm participação na fatia de riqueza". Nesse sentido, o poder do capital econômico é substituído pelo poder do conhecimento científico, e a educação emerge como o processo que garante a equidade e o fim da exclusão. Tal equidade foi anteriormente destacada como necessária por Sasson.

A partir desse argumento, o discurso se desenvolve focalizando os processos educativos formais e não formais e direcionando-os a diversos públicos, como jovens, crianças, mulheres rurais, indígenas, etc. A melhoria da qualidade de vida e do padrão socioeconômico é a justificativa, e o tópico é a educação como processo, sem especificidades.

A partir da teoria de Foucault (1997) acerca do enunciado, é possível delinear quatro características do que ele denomina função enunciativa. Uma delas é o domínio associado, condição indispensável para que tal função enunciativa possa ter existência. O domínio associado abarca: a) uma série de formulações na qual o enunciado se inscreve; b) um conjunto de formulações ao qual o enunciado se refere, seja para repetir, confirmar, rejeitar, modificar tais formulações, mas sempre em um processo de reatualização; c) um conjunto de formulações que se tornam possíveis, ulteriormente, devido à emergência de um determinado enunciado, ou seja, um encadeamento futuro. Tais condições permitem indicar o domínio associado como um domínio de memória que permite os processos de reutilização, modificação e projeção dos enunciados que, dispersos no tempo, são retomados na formação dos objetos. Tal processo pode ser delineado nesse artigo quando é citada a vinculação desses objetivos ao que foi proposto no Fórum Mundial sobre Educação realizado em Dacar no ano 2000. Esse documento apresenta propostas amplas de alfabetização de adultos e escolarização infantil até o ano de 2015, sem especificação da educação científica.

No contexto da América Latina, a discussão deve incluir algumas variáveis:

Enunciado 04 - No entanto, devemos ter consciência de que a região da América Latina e do Caribe se caracteriza por uma grande iniqüidade na distribuição do conhecimento, a qual se traduz em desigualdade e injustiça social. De cada três 
pessoas que habitam essa região, pelo menos uma vive na pobreza, e 36\% da população subsiste com menos de dois dólares por dia. Para os 40\% mais pobres do povo latino-americano o progresso não tem sido evidente, nem se tem materializado em termos logísticos. Neste sentido, a desigualdade na distribuição de renda tem uma relação estreita com a desigualdade educacional [...] (p. 63).

O discurso vai, paulatinamente, vinculando a questão do conhecimento à questão da desigualdade social e econômica; e o conhecimento é uma questão educacional associada ao econômico, reforçada pela construção "iniquidade na distribuição do conhecimento", que se vincula a outra mais antiga, em filiação e paralelismo: "iniquidade na distribuição de renda". Os dados estatísticos reforçam tal construção, pois eles trazem números sobre o nível de pobreza, até que a afirmação das autoras, de forma direta, indica a associação proposta: "a desigualdade na distribuição de renda tem uma relação estreita com a desigualdade educacional". É possível complementar: a igualdade educacional propicia igualdade na distribuição de renda. Obviamente tais relações são muito mais complexas do que a argumentação imediata parece indicar.

Da importância das políticas de educação chegamos à questão da formação científica e tecnológica.

Enunciado 05 - Nesse quadro, a formação científica e tecnológica, que hoje nos parece indispensável para poder entender a vida quotidiana e nela atuar, é, também, privilégio de uns poucos (p. 64).

No contexto contemporâneo, tendo em vista a longa trajetória que a ciência consolidou desde a Revolução Científica, para o sujeito viver e agir no cotidiano é necessário conhecimento científico. A ciência expande seu campo de atuação vinculando-se não somente ao espaço de conhecimento acadêmico, mas valorizando-se no campo da vida diária do sujeito comum.

Vinculando-se a outro documento internacional, a Declaração de Budapeste, o artigo apresenta outro ponto do processo: a comunidade científica. Garantir o acesso à ciência, levando em consideração o acesso à informação científica e sua consequente transformação em conhecimento, traz benefícios também às comunidades científicas, na medida em que as carreiras nesse campo podem ser incrementadas. Tal estratégia também indica uma retroalimentação: forte educação científica - formação de cientistas - reforço da comunidade científica.

É interessantes destacar como a estrutura argumentativa de ligação entre a desigualdade social e econômica e o déficit em educação científica parece por vezes desconsiderar outros elementos de igual impacto nas relações de assimetria entre diferentes classes sociais e entre diferentes países.

\section{“A contribuição da educação secundária à formação de cidadãs e cidadãos para uma sociedade sustentável" por Daniel Gil Pérez. e Amparo Vilches}


Logo no início do artigo, a educação científica é associada à atitude responsável que, por sua vez, remete à questão da sustentabilidade, como indicado no título. Há? A retomada do argumento de maior conhecimento para fundamentar decisões no âmbito de C\&T no que tange às consequências do desenvolvimento científico para a humanidade. Parece faltar um verbo no período...

Um dos destaques do artigo é a apresentação da noção de 'situação do mundo', que funciona para explicar a globalidade dos problemas que afetam a sociedade e a responsabilidade dos educadores na formação de cidadãos críticos. Discursivamente, essa ideia é construída a partir de três estratégias: $1^{\text {a }}$ - os apelos de organismos internacionais para que os educadores participassem da formação de cidadãos críticos com relação aos problemas planetários. $\mathrm{O}$ ápice desse movimento foi a Cúpula das Nações que aconteceu durante a conferência Rio 92; $2^{\mathrm{a}}$ - nessa conferência, por meio da Agenda 21, os educadores foram conclamados, qualquer que fosse o campo de trabalho específico, a "tornar possível a participação cidadã na busca de soluções” (p.128). De acordo com esse pensamento, problemas enfrentados pela humanidade exigem mais do que informação; são necessários reflexão, debate, e visão global dos problemas; $3^{a}$ - a justificativa por tal posicionamento está no fato de que até a segunda metade do século XX as consequências dos "efeitos das atividades humanas ficavam compartimentados localmente” (p.128). No entanto, nas últimas décadas, muitos problemas adquiriram caráter global, fazendo com que “a 'situação do mundo' se tornasse um objeto direto de preocupação”. O que sustenta tal afirmação: está presente nos relatórios de instituições internacionais (como o Worldwatch Institute), em reuniões e conferências mundiais, e no próprio Programa das Nações Unidas para o Desenvolvimento: "Esta é a razão fundamental dos apelos feitos a todos os educadores — insistimos — para incorporarmos a situação do mundo ao nosso trabalho docente" (p.129). As três afirmações sintetizadas funcionam para apresentar o argumento do enunciado que se articula em torno da educação científica.

Enunciado 06 - Qual a situação a este respeito, mais de uma década depois da Conferência do Rio de Janeiro? Como denunciava Orr (1995), até que ponto "continuamos educando os jovens, de modo geral, como se não tivesse havido uma situação de emergência planetária?” Apesar de apelos tão dramáticos, diversos autores têm lamentado a pouca atenção dada pela educação científica ao preparo dos estudantes para o futuro (HICKS e HOLDEN, 1995; TRAVÉ; POZUELOS, 1999; ANDERSON, 1999), assinalando que a maioria dos trabalhos sobre educação ambiental "focalizam exclusivamente os problemas locais, sem derivar para a globalidade" (GONZALES; ALBA, 1994). Indubitavelmente, continua faltando uma correta "percepção coletiva do estado do mundo" (p.130).

A ligação entre uma forte educação científica e a resolução de problemas futuros da humanidade, considerando o estabelecimento da 'situação do mundo’ como um fato a ser enfrentado, aparecem consolidadas pela força de 
uma 'emergência planetária' que impele os educadores a atuarem a partir de uma perspectiva mais global e coletiva. A noção de 'situação do mundo' sustenta o caráter mundial das ações educativas em ciência com vistas ao futuro do planeta.

\section{CONSIDERACְ̃̃ES PARCIAIS}

A harmonia dos elementos argumentativos entre os diferentes textos parece vir de uma filiação a uma conjuntura global, manifestada por diferentes documentos emanados de encontros internacionais e acordos entre diferentes nações. A educação científica e os processos que, atualmente, são compreendidos como necessários ao seu desenvolvimento - divulgação, popularização, alfabetização científica - emergem dos artigos analisados em uma relação que sustenta o fortalecimento da ciência como conhecimento hegemônico.

Uma das considerações que chegamos até o momento no desenvolvimento desta pesquisa, e tendo em vista a literatura da área e as análises dos documentos, é a de que quando a temática de educação científica surge, a ciência em pauta é representada pelas ciências exatas e da natureza. Qual o lugar das ciências humanas e sociais nesse contexto? Essa é uma pergunta para a qual não temos uma resposta exata, apesar de ser uma questão apontada por Snow (1995) em seu texto, considerado polêmico por muitos estudiosos da área, As duas culturas.

Uma segunda consideração diz respeito ao processo de intertextualidade que garante o reforço argumentativo dos textos em torno da relação entre educação cientifica e desenvolvimento social e econômico e fim das desigualdades. Desde o site da Unesco, passando pelos documentos citados nos artigos e pelo próprio documento em análise, a lógica de organização constrói uma cadeia que se manifesta de forma diferenciada em um ou outro texto, reforçando uma relação ou outra. Tal lógica pode ser expressa pela afirmação de que em uma sociedade fortemente moldada pela C\&T, a distribuição do conhecimento científico deve ser feita de forma igualitária. Nesse processo, especial atenção é dada ao aumento do volume informacional e a condição atual da escola como papel de difusora do conhecimento, emergindo discussões em torno dos espaços não formais. Somente essa distribuição do conhecimento científico pode garantir a igualdade social, via formação de cidadãos críticos que compreendam que o futuro do planeta está na problematização da "situação do mundo".

A relação entre o global e o local traduz a emergência de uma preocupação comum a todos e, ao mesmo tempo, de enfrentamento regional; a "situação do mundo" é globalizante; as respostas ao problema devem estar de acordo com a cultural local. A especificidade latino-americana demanda caminhos diferentes daqueles empreendidos pelos países europeus, por exemplo.

Mas, afinal, quais são os problemas a serem enfrentados? Dos artigos analisados, podemos destacar dois: a desigualdade social e econômica; o futuro do planeta. A princípio, esses dois problemas não parecem ter relação, no entanto, a 
questão da "situação do mundo" e a formação de cidadãos críticos releva que a educação científica é um elemento em relação com o desenvolvimento sustentável, esse é o termo-chave dos discursos sobre o ambiente e a sociedade. Para pensar sobre isso, basta retomar o enunciado 7, no qual lamenta-se sobre a pouca atenção dada à educação científica no preparo dos estudantes para o futuro.

Nossas considerações se situam entre o reconhecimento da importância da educação científica e a crítica à positividade das ciências exatas e da natureza como elementos únicos de desenvolvimento da perspectiva crítica e como único esteio para a "salvação do mundo". Admitimos que a educação científica deve estar pautada na emancipação, e que o desenvolvimento da capacidade crítica deve abarcar a autocrítica. A desigualdade, em qualquer nível, tem raízes históricas e fatores econômicos concretos que não podem ser esquecidos em discussões que incluem o aspecto educacional.

Um desses fatores é a forte relação entre o desenvolvimento capitalista e o desenvolvimento científico moderno, que hoje está presente, por exemplo, no posicionamento de diferentes países frente ao Protocolo de Kyoto: o controle de emissão de gases passa pela decisão de controlar os processos industriais que produzem esses poluentes.

Esse é somente um exemplo de como as questões fortemente econômicas, históricas e sociológicas estão, muitas vezes, presentes pela sua própria ausência como elemento de análise e discussão.

A rede de sentidos se forma na sustentação de uma educação científica que fomenta ações de formação humana e sustenta a emergência e a consolidação de uma cultura científica que se torna o ambiente no qual as decisões humanas devem ser guiadas por ações que têm a ciência como esteio.

\section{REFERÊNCIAS}

ALMEIDA, Miguel Osório. A vulgarização do saber. In: MASSARANI, Luisa; MOREIRA, Ildeu de Castro; BRITO, Fátima (Org.). Ciência e público: caminhos da divulgação científica no Brasil. Rio de Janeiro: Casa da Ciência, 2002. p. 65-72.

ARAÚJO, Elaine Sandra N.N; CALUZI, João José; CALDEIRA, Ana Maria de A. Divulgação científica e ensino de ciências. São Paulo: Escrituras, 2006.

AULER, D.; DELIZOICOV, D.. Alfabetização científico-tecnológica para quê? Ensaio Pesquisa em Educaşão em Ciências, v. 03, n. 01, 2001.

CHASSOT, Attico. Alfabetização científica: uma possibilidade para a inclusão social. Revista Brasileira de Educação, n.22, p. 89-100, 2003.

DUCROT, O. Enunciação. In: Enciclopédia Einaudi. Lisboa: Imprensa Nacional, Casa da Moeda. v. 2, Linguagem-Enunciação, 1984.

DURANT, John. O que é alfabetização científica? In: MASSARANI, Luisa; TURNEY, Jon; MOREIRA, Ildeu de Castro. Terra Incógnita. Rio de Janeiro: Vieira e Lent; UFRJ, Casa da Ciência: FIOCRUZ, 2005. p 13-26

EPSTEIN, Isaac. Divulgação cientifica - 96 verbetes. São Paulo: Pontes, 2002.

FOUCAULT, Michel. Arqueologia do poder. Rio de Janeiro: Forense, 1997. 
FOUREZ, G. Scientific and technological literacy as a social practice. Social studies of science, London: SAGE, v.26, n.5, dez. 1996. p. 903-936

FURIÓ, C., VILVHES, A., GUISASOLA, J., ROMO, V., (2001). Finalidades de la enseñanza de las ciencias en la secundaria obligatoria. ¿Alfabetización científica o propedéutica? Enseñanza de las ciencias, v. $19, \mathrm{n}^{\circ} 3$, p. 365-376, 2001

GRIGOLETTO, E. O discurso de divulgação científica: um espaço discursivo intervalar. 2005. 269f. Tese (Doutorado) - Programa de Pós-Graduação em Letras, Instituto de Letras, Universidade Federal do Rio Grande do Sul, Porto Alegre, 2005.

MACEDO, Beatriz; KATZKOWICZ, Raquel. Educação científica: sim, mas qual e como? In: MACEDO, Beatriz (Org.) Cultura científica. Brasília: Unesco, 2003.

MAINGUENAEU, D. Novas tendência em análise do discurso. Campinas: Pontes, Editora da UNICAMP, 1997.

OLIVEIRA, Carmen Irene C. de; ORRICO, Evelyn Goyannes Dill. Memória e discurso: um diálogo promissor. In: GONDAR, Jô; DODEBEI, Vera (Orgs) O que é memória sócia? Rio de Janeiro: Contra Capa, 2005. p. 73-87.

ORLANDI, Eni. Análise de Discurso: princípios e procedimentos. Campinas, SP: Pontes, 1999.

OSAKABE, H. Argumentação e discurso politico. São Paulo: Martins Fontes, 1999.

PÉREZ, Daniel Gil; VILCHES, Amparo. A contribuição da educação secundária à formação de cidadãs e cidadãos para uma sociedade sustentável. In: MACEDO, Beatriz (Org.) Cultura científica. Brasília: Unesco, 2003.

PEREZ, José Rafael Boesso; CALUZI, João José. A divulgação científica e o ensino de ciências. In: ARAÚJO, Elaine Sandra N.N; CALUZI, João José; CALDEIRA, Ana Maria de A. Divulgação cientifica e ensino de ciências. São Paulo: Escrituras, 2006.

Representação da Unesco No Brasil. Educação Científica no Brasil. Disponível em: <http://www. unesco.org/pt/brasilia/natural-sciences-in-brazil/science-education-in-brazil/. Acesso em?

RICOEUR, P. Teoria da significação. Lisboa: Edições 70, 1999.

SÁNCHEZ MORA, Ana María. A divulgação da ciência como literatura. Rio de Janeiro: Casa da Ciência, Editora da UFRJ, 2003.

SANTOS, Wildson Luiz Pereira. Educação científica na perspectiva de letramento como prática social: funções, princípios e desafios. Revista Brasileira de Educação, v.12, n.36, set./dez., 2007.

SASSON, Albert. A renovação do ensino das ciências no contexto da reforma da educação secundária. In: MACEDO, Beatriz (Org.) Cultura científica. Brasília: Unesco, 2003.

SERRES, Michel. Historia de las ciencias. Madrid: Cátedra, 1991

SILVA, Gilson Antunes da; AROUCA, Maurício Cardoso; GUIMARÃES, Vanessa Fernandes. As exposições na divulgação científica. In: MASSARANI, Luisa; MOREIRA, Ildeu de Castro; BRITO, Fátima (Orgs). Ciência e público: caminhos da divulgação científica no Brasil. Rio de Janeiro: Casa da Ciência, Ed. da UFRJ, 2002. p. 155-164.

SNOW, C.P. As duas culturas e uma segunda leitura: uma versão ampliada das Duas Culturas e a Revolução Científica. São Paulo: Editora da Universidade de São Paulo, 1995.

STRACK, R.; LOGUÉRCIO, R.; DEL PINO, J. C. Percepções de professores de ensino superior sobre a literatura de divulgação científica. Ciência \& Educaşão, v. 15, n. 2, p. 425-42, 2009.

UNESCO. Science Education Programme. Disponível em: < http://www.unesco.org/new/en/naturalsciences/priority-areas/science-education/about-the-programme/>. Acesso em: novembro de 2010.

VOGT, Carlos; POLINO, Carmelo (Orgs). Percepção pública da ciência: resultados da pesquisa na Argentina, Brasil, Espanha e Uruguai. Campinas: FAPESP, Ed. Unicamp, 2003.

WERTHEIN, Jorge. Apresentação. In: MACEDO, Beatriz (Org.) Cultura cientificica. Brasília: Unesco, 2003.

Data do Recebimento: 26/01/2012

Data de Aprovação: 13/10/2012

Data da Versão Final: 28/10/2012 